\title{
Algunas consideraciones en torno a la transdisciplinariedad y a la educación superior
}

\section{Some Considerations on Transdisciplinarity and Higher Education}

\author{
Luz Mary Arias Alpizar \\ Sede del Pacífico de la Universidad de Costa Rica \\ Puntarenas, Costa Rica \\ luzmaryarias@gmail.com \\ Oriester Abarca Hernández. \\ Sede del Pacífico de la Universidad de Costa Rica \\ Puntarenas, Costa Rica \\ oriesterabarca@gmail.com
}

Recibido 12 de mayo de 2010 • Aceptado 24 de junio de 2010

\begin{abstract}
Resumen. Durante los últimos dos siglos se ha venido sosteniendo la neutralidad y apoliticidad de la ciencia, pero se ha pasado por alto que esta, como construcción humana, no puede ostentar un estatus especial. Es decir, está condicionada históricamente al igual que cualquier otra actividad. La ciencia moderna adquirió su actual división disciplinaria en el siglo XIX, en gran parte por el desarrollo del capitalismo industrial que cubrió el orbe y la conformación de estados-nación y su organización dentro del sistema interestatal, de modo que es una particular forma de entender y estudiar la realidad, pero no la única posible. Las elecciones teóricas y metodológicas hechas desde entonces se han impuesto como la forma natural de aprehender la realidad.

La fase actual del proceso de la globalización ha puesto de manifiesto que el marco epistemológico decimonónico -y como parte de él, el nacionalismo metodológico- resulta insuficiente en el presente para explicar ciertos fenómenos sistémicos y ha revelado la necesidad de su superación.

En el presente contexto histórico se hace más necesario que nunca superar la dependencia académica y la adopción de una actitud crítica para que la división internacional del trabajo académico y la estructuración de una agenda transnacional para la educación no operen en contra de las zonas y poblaciones pobres del mundo. Ello supone que la universidad defina su papel con respecto a la sociedad desde una dimensión política, antes de que decida y realice su propia reforma. La transdisciplinariedad juega un papel principal en la superación de los viejos modelos de la ciencia y la universidad.
\end{abstract}

Palabras clave. Universidad, transdisciplinariedad, dependencia académica, nacionalismo metodológico, difusionismo.

\footnotetext{
Profesora adjunta de la Universidad de Costa Rica. Licenciada en Banca y Finanzas y Máster en Administración de Empresas, Licenciada en Docencia y Máster en Administración Educativa. Profesora de la Universidad de Costa Rica, Sede del Pacífico (Puntarenas), actualmente en las cátedras de Didáctica I y II e Introducción a la pedagogía. También se ha desempeñado como profesora de grado de la carrera de Dirección de Empresas. Actualmente es la Coordinadora de Estudios de Posgrado y de Asuntos Internacionales de la Sede del Pacífico de la Universidad de Costa Rica. Áreas de investigación y temas en que ha publicado: globalización y educación, epistemología y sociología de la ciencia, currículo multicultural, triangulación y transdisciplinariedad.

2 Profesor Asociado de la Universidad de Costa Rica. Licenciado en Derecho, Máster en Derecho Económico, Licenciado en Docencia y Máster en Administración Educativa; doctorando en Historia (Universidad de Costa Rica) y en Dirección de Empresas (Universidad de Valencia, España). Imparte en la Sede del Pacífico de la Universidad de Costa Rica los cursos de Economía Internacional, y Banca y Finanzas; y en la Facultad de Derecho de esa misma Universidad el curso de Filosofía del Derecho. Áreas de investigación y temas en que ha publicado: filosofía política, filosofía del Derecho, administración.
} 


\begin{abstract}
Over the past two centuries, it has been claimed that science is neutral and apolitical, without considering that, as a human construction, it cannot hold a special status. That is, it is historically conditioned as any other activity. Modern science acquired its current disciplinary division in the nineteenth century, largely because of the development of industrial capitalism that covered the globe and the formation of nation states and their organization within the interstate system. Thus, it is a particular way of understanding and studying reality, but not the only one. The theoretical and methodological choices made during this period have been imposed as the natural way of apprehending reality.

The current phase of the process of globalization has shown that, the nineteenth-century epistemological framework, and the methodological nationalism as part of this framework, is insufficient to explain systemic phenomena and revealed the necessity to transcend it.

In this historical context, it is more important than ever to overcome academic dependency, and to adopt a critical attitude for international division of academic work, and the structuring of an agenda for transnational education so as not to be detrimental to the poorest areas and populations of the world. This means that, the university should define its role with regard to society from a political dimension, before deciding and making its own transition to a reform. Transdisciplinarity plays a major role in overcoming the old models of science and university.
\end{abstract}

Key words. University, transdisciplinarity, academic dependency, methodological nationalism, diffusion.

"El ámbito de la educación superior es la cuna de las ideas; la disminución o la extinción de este ámbito necesariamente hace a una sociedad parásita de otras por sus ideas, y una sociedad parasitaria no puede permanecer libre"

(Patnaik, 2005, p. 102)

\title{
1. Introducción
}

La universidad, como institución, tiene, una responsabilidad social que no debe eludir. En ese senido la ciencia debe ser comprendida en su historicidad, es decir, como un producto humano que no puede ser apolítico. Las teorías y los métodos son elecciones que reflejan un determinado contexto y que producen consecuencias prácticas que con frecuencia pasan desapercibidas, aunque, a pesar de ese hecho, no dejan de estar presentes. Desde ese punto de vista, la transdisciplinariedad supone una elección política (en el más amplio sentido del término). A su vez, el papel de la universidad en el contexto de la globalización requiere ser determinado en el plano de las políticas, para luego atender los aspectos estratégicos y tácticos, como la reforma universitaria, la innovación de los enfoques didácticos o la reforma curricular en general.

El documento consta de nueve secciones. La segunda y tercera exponen, respectivamente, que ni la ciencia ni las disciplinas son ámbitos autónomos, neutros o ahistóricos de la realidad. La dependencia académica, como manifestación de la hegemonía política y de la división internacional del trabajo académico, se discute en la cuarta sección. En la quinta sección se propone la teoría crítica como un medio de superar la dependencia académica y los enfoques puramente tecnocráticos de la educación. La sexta sección plantea la existencia de una división internacional del trabajo de la gobernanza de la educación, lo que se examina desde el fenómeno del difusionismo. El nacionalismo metodológico, un elemento heredado de los supuestos epistemológicos del siglo XIX, que limita la visión de los procesos que ocurren a escalas diferentes a la del estado-nación, se discute en la sétima sección. La octava se refiere al papel de la universidad en la sociedad, el cual debe ser definido, en primer lugar, en el plano político. La última expone las conclusiones. 


\section{2. ¿Ciencia autónoma, neutra y ahistórica?}

Toda forma de ciencia se produce en un contexto específico; su contextualidad le impide ser apolítica. No hay ciencia neutra en términos históricos, políticos y sociales: la ciencia no es avalorativa (Putnam, 20023). Al igual que sucede con los conceptos y clasificaciones con que recortamos los diversos objetos y los agrupamos para los más diferentes fines, la actual división del conocimiento en disciplinas responde a una determinada forma histórica de entender y actuar sobre la realidad, como un proceso constructivo y contingente a la vez.

La ciencia participa en la construcción social de la realidad; pero, a menudo, se omite esta consideración de la teoría y de la práctica de algunos académicos, al pretender dotar al conocimiento científico de asepsia política. Cualquier discusión sobre la actual estructuración disciplinaria de la ciencia ha de pasar por el tamiz de la historicidad de esta y de sus productores: universidades, empresas transnacionales, investigadores independientes, críticos, evaluadores, entre otros, en un determinado contexto ${ }^{4}$.

Ello supone que lo inter, multi y transdisciplinario no es un asunto puramente cognoscitivo sino primariamente sociológico y político, de modo que el debate sobre dicha materia debe considerar los aspectos condicionantes derivados del contexto de producción, así como los resultados prácticos del conocimiento científico; en consecuencia, es necesario superar la distinción de Reichenbach (1938) entre contexto de descubrimiento y contexto de justificación ${ }^{5}$.

La actual división disciplinaria de la ciencia, establecida en el siglo XIX (Comisión Gulbenkian, 2007 [1996]; Wallerstein, 2001), tanto por los industriales como por los gobiernos de los estados metropolitanos (Bowen, 1992), ha sido funcional al sistema capitalista. La especialización y división en disciplinas obedeció al requerimiento de poner la ciencia al servicio de la industrialización, por medio de la tecnología; así, a pesar de que a principios del siglo XIX el holismo ${ }^{6}$ prevalecía, fue pronto sustituido por una perspectiva positivista y disciplinaria (Bowen, 1992), lo que también condujo a la pretensión de atribuir a la ciencia una condición avalorativa y a la idea de que la ciencia no tiene una responsabilidad social o es un ámbito neutro, autónomo de la realidad social. El regreso a lo holístico supone entender el proceso histórico que condujo a su negación. Lo transdisciplinario, en consecuencia, va más allá de una propuesta epistemológica.

La división de la ciencia en las actuales disciplinas respondió a condiciones históricas en el desarrollo del capitalismo, ligado a la concepción y desarrollo institucional del estado-nación. Según Wagner (2004), en el siglo XIX:

Angelides (2004), refiriéndose a Putnam, afirma: “(...) él intenta mostrar no solo que las prácticas de las ciencias presuponen prácticas y juicios normativos, sino también que la objetividad no puede ser separada de tales prácticas (...) el discurso de la objetividad (...) es, desde su punto de vista, mera fantasía” (p. 406). Según Putnam (2002), la distinción entre hechos y valores y su elevación a dicotomía metafísica, como a menudo ocurre en el ámbito de la Economía, puede llevar a decisiones políticas desastrosas.

4 Este ensayo se basa principalmente en la perspectiva interaccional de la sociología de la ciencia; véase al respecto Lamo de Espinoza, González y Torres (1994), así como Brunet y Pastor (2003). También son importantes algunos de los aportes recientes de la perspectiva institucional (véase Fernández y Torres, 2009).

Véase al respecto Bárcenas (2002).

6 El holismo, en términos metodológicos, se entiende como “(...) la tesis según la cual las totalidades deben estudiarse y entenderse en su propio nivel más que en términos de sus partes" (Bunge, 2005, p. 99). Entender la realidad como una totalidad supone superar el límite analítico impuesto por la especialización y la división de la ciencia en disciplinas. 
(...) a las emergentes instituciones de investigación se les otorgó una misión nacional y en parte fueron legitimadas por ella, [así] el estado-nación emergente reclamó no solo el monopolio de la legítima violencia (...) sino también el control sobre las pretensiones de conocimiento válido". (Wagner, 2004, p. 19)

La particular forma organizacional que asumieron los departamentos de las universidades y los centros de investigación produjo una departamentalización de la producción del conocimiento por disciplinas.

Existe una relación directa entre formación del estado-nación, modernidad y conocimiento científico:

Es evidente que el concepto de conocimiento académico y científico que prevaleció durante gran parte del siglo XX estuvo inextricablemente ligado a las formas decimonónicas - universidad y disciplina-, y que esas formas, a su vez, dependieron del estado-nación como el principal organizador de las instituciones científicas y, a la vez, como el proveedor (histórico) de lo que a menudo se denomina autonomía académica. (Charle, Schriewer y Wagner, 2004, p. 10)

La división social del trabajo alcanzó al conocimiento de manera tajante; la especialización debía hacer más eficiente la producción de conocimiento y su aplicación, pero en la medida en que se crearon diversas disciplinas, también se crearon diferentes vocabularios, metodologías, horizontes temporales, tendencias teóricas y ámbitos pretendidamente "autónomos". Así, "(...)lo que empezó como un intento de hacer que un gran problema fuera más manejable al crear conocimiento especializado, puede resultar en nuestra inhabilidad colectiva de llevar tales conocimientos de regreso a las preguntas para cuya respuesta fueron creados" (Denemark, 1999, p. 46).

La actual separación de las ciencias responde, así, a condiciones históricas, tanto materiales como a usos ideológicos ${ }^{7}$.

\section{3. ¿Disciplinas autónomas, neutras y ahistóricas?}

La pretensión de que la ciencia es un ámbito autónomo de la realidad y es, por lo tanto, neutra, se reproduce en el nivel de las disciplinas. Una consecuencia de esta pretensión de autonomía de las disciplinas es lo denominado por Dale (2005) como "parroquialismo institucional", esto es, la tendencia a abordar un tema exclusivamente desde dentro de un campo. Esta concepción conduce a análisis que asumen o comparten la definición del tema en los términos en que ha sido planteado en ese campo y deja poco espacio para problematizarlo teóricamente sobre la base de los enfoques de otras disciplinas ${ }^{8}$.

Según Bloor (1982) “(...) todos nuestros conceptos, clasificaciones y teorías son formas de inducción estructuradas socialmente y convencionalmente canalizadas”. Y “(...) cuando los hombres piensan sobre la naturaleza, lo que están haciendo es reflejar indirectamente los principios de acuerdo con los cuales está organizada la sociedad. Realmente están manipulando tácitamente imágenes de la sociedad”. (citado por Brunet y Pastor, 2003, p. 148)

8 Específicamente respecto al campo de la Educación, Dale (2005) expresa: “(...) por parroquialismo institucional me refiero a la tendencia dentro de todos los estudios de educación, incluyendo la educación comparada, a: a) hacer de los sistemas de educación, instituciones y prácticas existentes, considerados de forma aislada, el foco dominante de sus análisis, y b) no problematizar estos sistemas, instituciones y prácticas sino asumir que la equivalencia léxica es suficiente garantía de que los objetos en estudio son suficientemente similares para hacerlos comparables sin mayor investigación adicional”. (p. 134) 
Tómese como ejemplo la separación entre economía y política, producida a partir de la segunda mitad del siglo XIX. Al sustituir Economía política por Economía (sin adjetivo), “(...) los economistas podían sostener que el comportamiento económico era el reflejo de una psicología individual universal, y no de instituciones socialmente construidas, argumento que a continuación podía utilizarse para afirmar la naturalidad de los principios de laissez-faire" (Comisión Gulbenkian, 2007 [1996], p. 20). De esta forma, la Economía pasó a considerarse, desde la perspectiva de los neoclásicos, un ámbito autónomo, un dominio que debía ser estudiado de manera separada de otros fenómenos sociales. Tal autosuficiencia llevó a una concepción nomotética ${ }^{9}$ de la Economía. El resultado fue la esterilización de la misma disciplina, la cual dejó de plantearse una serie de preguntas de orden social y ético, y las sustituyó por problemas de índole matemática o axiomática y, en muchos casos, una construcción basada en supuestos puramente normativos ocultos bajo la pureza formal de sus modelos. Es notable que el fracaso de los modelos neoclásicos en la situación de las últimas dos décadas haya conducido a un nuevo redireccionamiento hacia la Economía política y, no es de extrañar, que esta nueva dirección se haya producido desde los estudios de las relaciones internacionales, a partir de propuestas como las de Cox (1996) o las de Strange $(1996,1997)$. El reto que representa la globalización para los enfoques disciplinarios tradicionales -no solo para la disciplina económicaha llevado a generar una nueva actitud en muchos académicos y a un giro en las teorías.

Para Bögenhold (2008):

Estamos experimentando una situación de creciente crítica del estado en que hoy se encuentra representada la Economía. Una de las observaciones es que la Economía ha devenido demasiado formalizada y abstracta y que el estado de la disciplina es cada vez más incapaz de expresar muchos fenómenos de la "vida real" en términos de concretas especificaciones socioeconómicas, culturales, regionales e históricas. En este sentido, la crítica se ha clasificado en términos de "Economía heterodoxa", "Economía posautista", Socioeconomía o Institucionalismo, que son nuevas plataformas para describir enfoques alternativos. La pretensión de fomentar la investigación interdisciplinaria, que también encontramos en tiempos recientes, refleja el mismo diagnóstico de que nuestras islas de conocimiento compartido se han vuelto demasiado fragmentadas. (pp. 85-86)

Esta crítica no es nueva: ya para finales del siglo XIX Veblen $(1909,2007)$ dirigía su obra contra la tendencia, en la investigación económica, a crear modelos abstractos y ahistóricos. Schmoller sostenía, en 1883, contra el formalismo de Menger (1976), que la investigación empírica debía llevarse a cabo primero y que las relaciones económicas únicamente podían entenderse por medio del conocimiento de las realidades históricas de las economías. Por su parte, los economistas ortodoxos argumentan que un supuesto (an as if assumption) es suficiente si sus predicciones son exactas. Así, contra la acusación de que los supuestos de los modelos de la economía neoclásica son poco realistas, Friedman (1953) apuntaba que lo que importa es que sean buenas aproximaciones en un grado suficiente para el propósito en manos, lo cual solo puede contestarse examinando si la teoría funciona, es decir, si produce predicciones suficientemente $\operatorname{correctas}^{10}$. En la crítica

Sobre la división de las ciencias en nomotéticas e idiográficas véase el interesante artículo de Salas (2005). Tal división es parte de las visiones fragmentarias que es necesario vencer.

10 Sobre el tema del método en la Economía ortodoxa véase Blaug (1992). Según dicho autor, la mainstream declara su adhesión al falsacionismo popperiano, pero es inconsecuente con dicha teoría, en especial en lo que respecta a someter a constatación directa sus supuestos fundamentales y afirma: "Soy crítico de lo que los economistas realmente hacen, como algo distinto de lo que dicen hacer" (1992, p. xiii). Expresa García-Bermejo (2005) "Blaug hace suya la idea de que la teoría económica se estaría cultivando cada vez más como un puro juego intelectual, sin ninguna pretensión de arrojar ninguna luz sobre la economía efectiva”. (p. 119) 
de esta racionalidad economicista incluso se ha llegado a cuestionar el lenguaje y métodos de la Economía, examinándolos como recursos retóricos (McCloskey, 1989) destinados a persuadir a una audiencia.

La concepción de la Economía, por parte de los neoclásicos, como un ámbito autónomo respondió a factores tanto exógenos como endógenos a la academia. En lo externo, el predominio de la idea liberal del libre mercado llevó a la reificación ${ }^{11}$ de este y a la división institucional de lo político y lo económico. Según Polanyi (1997): “(...) un mercado autorregulador exige nada menos que la división institucional de la sociedad en una esfera económica y en una esfera política" (pp. 126127). Para Schmitt la concepción liberal de la sociedad, predominante en el pensamiento occidental durante los últimos dos siglos, es responsable de tal separación. Pero la negación de lo político constituye en sí mismo un proceso político ${ }^{12}$. Para superar el enfoque puramente disciplinario, hay que empezar por reconocerle a la ciencia ese papel político del cual no puede abstraerse, aun si en su discurso se declarara neutral. El punto de arranque, entonces, es tener la honestidad intelectual de reconocer explícitamente los fundamentos normativos (en última instancia, políticos) de las concretas materializaciones históricas de la ciencia y las consecuencias que de ellos se derivan para la colectividad en sus diferentes escalas.

Lo anterior va unido a la idea de reflexividad. Según Bourdieu (2003), la reflexividad busca "objetivar al sujeto de la objetivación” y permite dar cuenta de los límites y la posición del científico social en la sociedad, en el campo y en el ámbito académico general. La reflexividad aplica para el científico y para sus teorías. Una teoría cumple con el criterio de reflexividad cuando: "a) tiene conciencia de las permisas subyacentes, b) reconoce la dimensión político-normativa de los paradigmas y de la tradición de ciencia normal que sustentan y c) acepta la posibilidad de considerar ponderadamente los méritos de paradigmas enfrentados pese a la ausencia de un lenguaje de observación neutro" (Neufeld, 1993, p. 55).

El problema de lo disciplinario también tiene un componente institucional (Kuhn, 1962; Merton, 1973; Bloor, 1982; Bourdieu, 2003; Frickel y Gross, 2005). La organización institucional de las academias es en gran parte responsable de la departamentalización del conocimiento en disciplinas:

Las disciplinas difícilmente sobrevivirán sin el apoyo de las instituciones -sean estas universidades, academias, institutos de investigación o cualquier otro tipo de estructura organizacional-, pues ellas proporcionan las plazas de trabajo y la infraestructura necesarias para las publicaciones, garantizando con ello la continuidad del trabajo académico. De forma similar, y dado que las disciplinas académicas no son lo mismo que comunidad disciplinaria, no puede pensarse a las primeras sin el tipo de sustrato social de la segunda, pues las disciplinas académicas descansan sobre grupos delimitados de gente que se reúne (porque comparte intereses o motivos), especialmente en el contexto de conferencias periódicas, grupos de estudio, instituciones universitarias extramuros, asociaciones de profesionistas o sociedades académicas. (Schriewer y Keiner, 1997)

\footnotetext{
Cabe recordar las palabras de Sørensen (1998): "No es la aceptación de la existencia real de fenómenos sociales lo que produce la reificación objetivista. La reificación se produce por la transformación de fenómenos sociales históricamente específicos en condiciones dadas, ahistóricas y naturales". (p. 87)

12 Escribía Schmitt en 1932: "El liberalismo del último siglo ha arrastrado consigo una singular y sistemática transformación y desnaturalización de todas las ideas y representaciones de lo político. Como realidad histórica que es, el liberalismo ha podido sustraerse a lo político en la misma escasa medida que cualquier otro movimiento humano de consideración, y también sus neutralizaciones y despolitizaciones (de la educación, de la economía, etc.), poseen un sentido político" (citado por Ibánez, 2002, p. 59).
} 
El conocimiento científico es un producto socialmente construido en el cual un gran peso corresponde a las "culturas de las academias" (Clark, 1983; Cameron y Ettington, 1988; Austin, 1990; Peterson y Spencer, 1990; Dill, 1991; Tierney y Rhoads, 1994; Frost y Jean 2003) como fuerzas que influencian las actitudes y prácticas de las facultades. Tales fuerzas incluyen patrones de actitudes, significados, símbolos y conductas que se funden alrededor de las disciplinas, las instituciones y la profesión ${ }^{13}$.

Las culturas de las academias, cuando suponen un significativo grado de resistencia al cambio, representan un serio desafío para las propuestas inter, multi y transdisciplinarias. De manera que si una propuesta no obtiene el beneplácito de los grupos dominantes de la comunidad académica, tiene muy pocas probabilidades de ejercer alguna influencia, tanto en términos teóricos como prácticos. Al respecto, Frickel y Gross (2005) plantean una serie de proposiciones generales que aplican a los "movimientos científicos e intelectuales" (SIM por sus siglas en inglés):

Proposición I: Un SIM tiene más probabilidades de surgir cuando actores de un elevado status intelectual acogen reclamos contra lo que entienden como tendencias intelectuales centrales de la época. (p. 209)

Proposición II: Los SIM tienen más probabilidades de ser exitosos cuando las condiciones estructurales proveen acceso a recursos claves. (p. 213)

Proposición III: Cuanto mayor es el acceso de un SIM a varios contextos de micromovilización, mayor es su probabilidad de ser exitoso. (p. 219)

Proposición IV: El éxito de un SIM depende del trabajo realizado por los participantes en el movimiento para enmarcar las ideas de este en formas que resuenen con los intereses de aquellos que habitan uno o varios campos intelectuales. (p. 221)

Sin duda, estas proposiciones pueden complementarse con el concepto de Bourdieu (2003) de campo científico -que entiende como el lugar de lucha política por la dominación científica- y con su tesis de que los métodos son a la vez estrategias científicas y políticas. Al respecto también resulta pertinente el análisis de la retórica de la ciencia y el reconociendo del papel del discurso científico -aunque no exclusivamente- como un medio de persuasión ${ }^{14}$, para desmitologizar a la ciencia como sustituto de la autoridad de la religión ${ }^{15}$ y asumirla en su dimensión de producto histórico y, por ello, sujeta a los mismos condicionamientos y falencias de otros productos humanos.

\footnotetext{
13 "La cultura de la disciplina, por ejemplo, consta de una 'tradición de conocimiento' que incluye categorías de pensamiento, un vocabulario común y los correspondientes códigos de conducta. La cultura de la institución rodea a cada universidad, generando la lealtad por medio de símbolos de unidad y permitiendo al mismo tiempo que diversas subculturas florezcan. La cultura de la profesión influye en todas las disciplinas e instituciones, proporcionando las bases para una sola 'comunidad de estudiosos'. En el curso normal de la interacción intelectual, estas fuerzas se cruzan, chocan, se dividen, o refuerzan el trabajo de las facultades" (Frost y Jean, 2003, p. 120). Si bien cultura es un término polisémico, Toma (1997, p. 682) enlista algunas de las definiciones que diversos autores han ofrecido: a) Filosofías, ideologías, valores, supuestos, expectativas, actitudes y normas que son compartidos dentro de una comunidad. b) Los patrones colectivos, apoyados mutuamente, de normas que guían la conducta de individuos o grupos. c) El entendimiento tácito acerca de lo que es importante. d) Redes de significado tejidas por los humanos. e) Patrones de supuestos básicos inventados, descubiertos o desarrollados al aprender a resolver problemas. f) Los patrones compartidos de significados que mantienen unido a un grupo.

14 Como afirma Bazerman (1988) “(...) la persuasión está en el corazón de la ciencia, no en uno de sus bordes menos respetables. Una retórica inteligente, practicada dentro de una comunidad de investigadores seria, experimentada, conocedora y comprometida, es un método serio de buscar la verdad". (p. 321)

15 Sobre la autoridad que ha adquirido la ciencia como un componente de la política mundial y cultural en el sistema moderno, véase Drori, Meyer, Ramírez y Schofer (2006). El enfoque institucional que exponen dichos autores entiende ciencia no como un conjunto de verdades objetivas sino como "(...) aquellas actividades que las organizaciones relevantes y las pautas discursivas aceptan como tal" (p. 16). Más que por logros específicos, la ciencia moderna ha adquirido un status privilegiado por la autoridad y legitimidad que ha logrado alcanzar: "Los elementos esenciales de la ciencia, difundidos a través de los dominios sociales y en todo el mundo, radican y son el resultado de la autoridad cultural institucionalizada de la que ha sido investida, en mucha mayor medida que cualquier otro desarrollo organizativo y profesional concreto". (Drori, Meyer, Ramírez y Schofer, 2006, p. 20)
} 


\section{Dependencia académica}

Un claro riesgo que se asume al adoptar el discurso de la transdisciplinariedad, sin un sentido crítico del "para qué", es caer en una forma más de dependencia académica. La división global ${ }^{16}$ del trabajo intelectual, junto con otros factores, ha generado la dependencia académica de unas regiones periféricas y semiperiféricas del mundo con respecto a un bloque central, representado en las ciencias sociales por Estados Unidos, Inglaterra y Francia. Las dimensiones de tal dependencia son, según Alatas (2003):

1. Dependencia de ideas.

2. Dependencia de los medios en que se expresan las ideas.

3. Dependencia de la tecnología de educación.

4. Dependencia de la ayuda exterior para la investigación y la enseñanza.

5. Dependencia de la inversión extranjera en educación.

6. Dependencia de los científicos tercermundistas de la demanda de Occidente de sus habilidades.

La dependencia de ideas se produce en los diferentes niveles de actividad de las ciencias sociales -metateoría, teoría, ciencia social empírica y ciencia social aplicada-, y es, para Alatas, la dimensión más importante de la dependencia académica, sin la cual las otras dimensiones carecerían de sentido. Se manifiesta en los países pobres como una carencia casi absoluta de análisis originales en los niveles de metateoría y teoría y, en el nivel empírico -en el que se produce un volumen considerable de trabajo- como la tendencia a seguir a la investigación que se realiza en el centro en términos de agenda de investigación, perspectivas teóricas y métodos.

El grado de dependencia académica, en la segunda dimensión, se puede medir a partir de la estructura de la propiedad y control de las editoriales, revistas, sitios de internet y otros medios. La tercera dimensión (dependencia tecnológica) limita el acceso y la selección de información a la de los sistemas de las organizaciones extranjeras que proveen esos servicios. La dependencia de la ayuda exterior para la investigación y la enseñanza se produce a partir de fondos dedicados al patrocinio de proyectos de investigación, compra de libros, revistas y otros materiales didácticos, publicación de libros y revistas locales y la contratación de servicios de profesores visitantes. La quinta dimensión se materializa en inversión extranjera directa, a menudo joint ventures, en instituciones locales. La fuga de cerebros (brain drain) es la sexta dimensión y puede suponer la reubicación física de los académicos, pero puede ocurrir sin ella ${ }^{17}$.

Aparte de las tres potencias que constituyen el centro en las Ciencias Sociales (Estados Unidos, Inglaterra y Francia), existe una semiperiferia, conformada, según Alatas (2003), por países como Australia, Japón, Holanda y Alemania, cuyas comunidades académicas no son dependientes en cuanto a las dimensiones económicas (segunda a sexta), pero sí en cuanto a ideas (primera

6 Si se utilizaran las categorías del nacionalismo metodológico la expresión sería: "La división internacional del trabajo intelectual ...”; pero esta nomenclatura se muestra cada vez más obsoleta.

17 Tales asimetrías han sido expuestas recientemente en un informe publicado conjuntamente por UNESCO y el Consejo Internacional de Ciencias Sociales (2010): el 75\% de las revistas especializadas se editan en América del Norte y Europa Occidental y el $85 \%$ se publican total o parcialmente en inglés; una cuarta parte se editan en Estados Unidos; además, las dos terceras partes de las revistas de Ciencias Sociales del mundo se editan en cuatro países: Estados Unidos, Reino Unido, Países Bajos y Alemania. La fuga de cerebros es otro problema que afecta las áreas pobres y beneficia las áreas metropolitanas del mundo: por ejemplo, en EE. UU. uno de cada tres doctores en Economía y casi uno de cada cinco doctores en Ciencias Sociales provienen de países extranjeros. 
dimensión). Esta semiperiferia la define Alatas (2003) como una comunidad científica que "(...) es dependiente de las ideas que se originan en los centros de las ciencias sociales, pero que ejerce a su vez alguna influencia en las comunidades científicas de la periferia por medio de la provisión de fondos, recepción de estudiantes de posgrado y posdoctorado en sus universidades, financiación de conferencias internacionales, etc." (p. 606).

Según la tesis de Alatas, existe una división global del trabajo respecto del conocimiento, lo que se muestra en tres aspectos:

a) El centro produce tanto teoría como investigaciones empíricas, mientras la producción de la periferia se limita, casi en su totalidad, a investigaciones empíricas.

b) Los académicos del centro realizan estudios tanto de su propio país como de otros países, mientras en la periferia los académicos tienden a limitarse a investigar sobre su propio país.

c) En el centro se presenta una frecuencia mucho mayor de estudios comparativos, mientras en la periferia predominan los estudios no comparativos de casos, los cuales, casi siempre, coinciden con el país del investigador.

El giro hacia lo transdisciplinario supone un cambio radical de la mentalidad de los académicos. En regiones periféricas como Latinoamérica, tal giro debe conducir a una superación de lo que Alatas (2004) denomina "mentalidad cautiva", que es aquella que extiende la aplicación de las ciencias sociales europeas y estadounidenses a su propio escenario sin una apropiada adaptación de las ideas y técnicas importadas. La mente cautiva "(...) carece de creatividad y de la habilidad para plantear problemas originales, se caracteriza por una perspectiva fragmentada, está alienada tanto de las cuestiones sociales fundamentales como de su propia tradición nacional y es consecuencia del dominio occidental sobre el resto del mundo" (Alatas, 2004, p. 61). Cabe, para los académicos de las regiones pobres del mundo, preguntarse si los instrumentos teóricos importados son los que su propia realidad requiere y cuáles son los intereses a los que tales propuestas sirven. Es decir, es necesario asumir una posición crítica, que también supone creatividad. El reto es crear una forma propia de ser transdisciplinarios, según las necesidades y exigencias del propio contexto. A este respecto es conveniente examinar la distinción entre teoría crítica y teoría de resolución de problemas que propone Cox (1996). La dependencia académica es acrítica y puede ser examinada también como una dimensión del fenómeno del difusionismo. Ambos aspectos se exponen en los dos siguientes apartados.

\section{Teoría crítica}

Cox (1996) distingue entre teoría de resolución de problemas (problem solving theory) y teoría crítica (critical theory).

La primera "(...) toma el mundo como lo encuentra, con las relaciones sociales y de poder prevalecientes y las instituciones en las que están organizadas, como el marco dado para la acción (...)" (Cox, 1996, p. 88); puesto que no cuestiona el estado actual de la sociedad, el objetivo general de la teoría de resolución de problemas es hacer que tales relaciones e instituciones operen sin dificultades, por medio de la resolución efectiva de problemas particulares, identificados y formulados desde la perspectiva de los dominios especializados de donde surgen; dominios que se encuentran fragmentados, unos en relación con otros. Se trata de una perspectiva analítica reduccionista. Aunque se presenta como avalorativa (value free) en términos metodológicos, no lo 
es, dado que implícitamente acepta el orden prevaleciente como su propio marco referencial. Su perspectiva es no-histórica o a-histórica, pues postula un presente continuo: esto es, las instituciones y relaciones de poder que constituyen sus parámetros. Su fortaleza, no obstante, es su capacidad para delimitar un área de problemas y enunciar un problema en términos de un número limitado de variables, bajo la presunción ceteris paribus, que “(...) hace posible llegar a proposiciones de leyes o regularidades que parecen tener validez general pero que suponen los parámetros institucionales y relacionales asumidos en el enfoque mismo de resolución de problemas" (Cox, 1996, p. 88).

Existe, en consecuencia, cierta circularidad en la teoría de resolución de problemas, puesto que la definición de problema, la forma de examinarlo y las soluciones que se eligen, dependen de los supuestos de los que parte, los cuales, básicamente, dan por válido el orden actual de cosas (es, en este sentido, una teoría irreflexiva).

Según Cox (1996), la teoría crítica, a diferencia de la anterior, pone en tela de juicio dicho orden y se pregunta por sus orígenes y proceso de cambio, asumiendo el complejo social y político como un todo, del cual la parte inicialmente considerada es solo un componente. Su enfoque es holista e histórico, no porque se interese por el pasado, sino por su interés en el continuo proceso de cambio, el cual aborda realizando un ajuste continuo de sus conceptos a los objetos cambiantes que trata de entender y explicar. Esto hace que los conceptos y los métodos de investigación usados parezcan imprecisos frente a los de la teoría de resolución de problemas; pero su fortaleza es aparente, pues se basa en la falsa premisa de que el orden político y social es fijo, lo cual, para Cox (1996), es un sesgo ideológico al servicio de los intereses nacionales, grupales o de clase, acomodados al orden existente.

Cox (1996) acepta que la teoría crítica contiene teorías de resolución de problemas en la forma de ideologías ${ }^{18}$ identificables, pero aclara que no las postula como guías para la acción, como sí lo hace la teoría de resolución de problemas con sus respectivas ideologías. En definitiva, la principal diferencia entre la teoría crítica y la de resolución de problemas es que la primera puede ser una guía para la acción estratégica dirigida al logro de un orden alternativo; mientras la segunda se constituye en una guía para acciones tácticas que, de manera intencional o no, mantienen el orden existente.

Lo que realmente define al concepto de teoría crítica propuesto por Cox es la reflexividad del proceso mismo de teorizar, es decir, cuando se toma clara conciencia de la perspectiva que origina la teorización y su relación con otras perspectivas para abrir la posibilidad de escoger una perspectiva válida diferente, desde la cual la problemática devenga en una oportunidad de crear un mundo alternativo.

Desde nuestro punto de vista, ninguna teoría es crítica per se, sino en relación con un determinado contexto en el cual las personas la aplican ${ }^{19}$. No hay contenidos intrínsecamente -sino contextualmente- críticos. En el contexto actual, la criticidad supone la creatividad para generar teorías, epistemologías y metodologías propias, actuando reflexivamente y respondiendo a las trayectorias históricas de nuestros pueblos y al contexto multiescalar de la globalización. Ninguna teoría es universalmente crítica; afirmar lo contrario sería caer nuevamente en la más

18 Cox, en 1968, había definido ideología de la siguiente manera: "El término ideología se usa en el sentido de una doctrina diseñada para producir una acción, una interpretación de la realidad que pretende ser una guía para la acción sobre ella. Las ideologías pueden ser limitadas en su alcance; por ejemplo, pueden limitarse a la educación y el desarrollo económico o al papel de las organizaciones internacionales en la política mundial, así como a interpretaciones globales del cambio histórico". (p. 314)

19 McCloskey (1989) ofrece el siguiente ejemplo: “'Las teorías críticas apuntan a la emancipación y a la ilustración'. Este propósito fue primordial en la mente de Adam Smith. La teoría emancipadora de Smith no fue un factor menor en la literal emancipación de los esclavos en el Imperio Británico. Y por supuesto, desde entonces ha sido el fundamento de un tipo de política anarquista, impopularmente antiestatista en un mundo estatista". (p. 111) 
pura abstracción, al atribuirle un carácter ahistórico - despojándola de las coordenadas de espacio y tiempo-. Ello supone, entre otras cosas, superar la dependencia académica y la mentalidad cautiva.

Las anteriores ideas, llevadas al ámbito de la universidad, remiten a los conceptos de Jantsch (1972). La estructura transdisciplinaria de la universidad, en su propuesta, se enfoca en el método y en principios organizativos generales, más que en conocimiento especializado acumulado. En el ámbito de la docencia, esto supone sustituir el entrenamiento para carreras y profesiones -que no hace más que duplicar habilidades ya existentes y opera por saturación de información, no pocas veces redundante, impertinente o irrelevante-, por una educación orientada a permitir el juicio crítico acerca de situaciones cambiantes, complejas y dinámicas. Respecto de la investigación, la consecuencia es entender y asimilar que "la creación de conocimiento no es la simple agregación de información, ello requiere juicios en nuevas situaciones que suponen no poco pensamiento lateral colectivo. Dicho de otra forma, es un proceso reflexivo que requiere una cultura de innovación en la cual pueda florecer" (Taylor, 2000, p. 1112).

La educación basada en la mera enseñanza de conocimiento acumulado hace énfasis en el know-how: en un saber-hacer definido como las capacidades de una organización o individuo para desarrollar habilidades técnicas precisas, aplicadas a áreas de trabajo específicas, es decir, se basa en una perspectiva de resolución de problemas y no en una perspectiva crítica. Con frecuencia tampoco asume la teoría como una forma de organizar el conocimiento existente y de orientar la investigación, lo cual es lamentable, si se considera que "el conocimiento siempre se relaciona a alguna manera de organizar la experiencia” (Eder, 2008, p. 25).

Esto ha generado serias consecuencias tanto en la docencia como en la investigación. Cuando ambos ámbitos se limitan a un nivel de resolución de problemas que atiende "(...) objetivos puramente técnicos, descuidando el carácter sistémico de la mayoría de estos problemas en el área social" (Jantsch, 1972, p. 10). Desde este nivel se considera a la ciencia y a la tecnología como instrumentos neutros y autónomos, y no se cuestionan las teorías, implícitas o explícitas que fundamentan los trabajos disciplinarios. Frente a ello, Cox ha manifestado que "(...) la teoría es siempre para alguien y para algún propósito. Todas las teorías tienen una perspectiva" (1996, p. 87, énfasis del original). Es decir, no hay teoría desinteresada ni neutra. Tomar conciencia de ello es parte de la construcción de teorías críticas que orienten la organización y quehacer de la universidad, según la idea de reflexividad (Bourdieu, 2003; Neufeld, 1993).

\section{Difusionismo}

De acuerdo con Dale (2005), se ha intentado desarrollar una teoría de la relación entre globalización y educación, basada en "(...) las ideas de una agenda estructurada globalmente para la educación y de una división -funcional, escalar y sectorial- del trabajo de gobernanza de la educación" (p. 138). Los hechos que están a la base de ambas ideas se pueden entender como una forma de difusionismo.

La difusión de modelos políticos y culturales es un fenómeno innegable y ha sido explicado desde enfoques y teorías tanto culturalistas como estructuralistas.

Se ha argumentado (Halperin, 2007) la existencia de élites que operan a nivel mundial como una red, las cuales tienen más elementos en común entre sí que con las propias clases sociales nacionales. Para Halperin ese hecho se debe a que la expansión del capitalismo, desde su inicio $\mathrm{y}$ en todo lugar, ha sido transnacional en naturaleza y global en alcance, $\mathrm{y}$ ha involucrado tanto 
a sociedades como a sectores, regiones y grupos en Europa, las Américas, Asia y África. Tal expansión se caracteriza por interacciones y conexiones trans-locales y relaciones y luchas locales (intrarregionales), y no por procesos centrados en imperios o estados-nación. Su propuesta es cambiar el enfoque vertical (estados, regiones) por uno horizontal (clases y redes) para analizar el desarrollo sincrónico e interdependiente de puntos focales dinámicos alrededor del mundo.

La propuesta teórica de Halperin permite el planteamiento de diversas hipótesis relativas a la difusión de modelos políticos y culturales, que se "copian" de un lugar a otro y a veces de una manera muy rápida. Si los miembros de estas élites (redes) locales y translocales (mundiales) forman una cierta unidad económica, política y cultural, entonces la difusión en cuestión parece obvia. La mayoría de los análisis que asumen el punto de vista tradicional (nacionalismo metodológico, estadocentrismo) consideran "lo social" como dividido en una multiplicidad de sociedades delimitadas nacionalmente, lo que ha oscurecido la existencia de tales relaciones reticulares y procesos mundiales. Para Halperin, las sociedades nacionales modernas fueron construidas sobre un campo social translocal, que no fue destruido por la aparición del estado-nación y que continúa cumpliendo, un papel y efectos independientemente de las fronteras, y que da dirección a las prácticas políticas, económicas y culturales en los diferentes lugares de manera muy similar ${ }^{20}$. Es claro que la educación no está exenta del influjo de horizontalidad del sistema mundial a que se refiere Halperin.

Existen diversas teorías, además de la de Halperin, desde las cuales se puede intentar examinar el fenómeno de la difusión de modelos económicos, culturales y políticos. Cabe plantear, de previo, una distinción entre difusionismo y teorías de la difusión. La idea del difusionismo ha ejercido influencia por casi los últimos dos siglos (Blaut, 1987). Su primera etapa inició hacia finales del periodo napoleónico y finalizó con la I Guerra Mundial. Cumplió el papel de dotar de fundamentos teóricos al colonialismo, al presentarlo como algo normal, natural, inevitable y moral. La segunda etapa inició luego de la II Guerra Mundial, al derrumbarse los imperios coloniales. Su énfasis se puso en la difusión de los modelos de los países desarrollados hacia los no desarrollados, como la única vía posible para el desarrollo de estos (la teoría de la modernización es un ejemplo de esta perspectiva). En ambos casos dichos modelos teóricos han cumplido una evidente función ideológica y, por lo tanto, pueden ser calificados de "difusionismo". Pero también ha habido otros productos, menos ligados a su directo uso por parte del poder: por ejemplo, Simmons y Elkins (2004), sobre la difusión de políticas en economía internacional; O’Loughlin, Ward, Lofdahl, Cohen, Brown, Reilly, Gleditsch, y Shin (1998) sobre la difusión de la democracia; Kobrin (1985) sobre el efecto dominó en la nacionalización petrolera; Kaufman y Patterson (2005), sobre la difusión de prácticas culturales; Rousseau y van der Veen (2005), sobre la construcción y difusión de identidades; Elkins y Simmons (2005) sobre los procesos de difusión de políticas de reforma. El número de estudios sobre la difusión como proceso o como producto ha sido significativo en las últimas décadas ${ }^{21}$.

20 Afirma Halperin (2007): "La mayoría de las perspectivas sobre el desarrollo toman como punto de partida analítico una concepción de lo 'social' como (ya) dividido en una multiplicidad de sociedades delimitadas nacionalmente. La 'sociedad' se refiere, la mayoría de las veces, a sociedades delimitadas 'nacionalmente'. Pero los estados territoriales de varios tipos y las modernas 'sociedades nacionales', se construyeron dentro de un campo social translocal preexistente. Este sistema de instituciones sociales, relaciones y normas no fue desplazado o destruido por el ascenso y caída de los estados y de los sistemas estatales: las fuentes translocales de poder y estabilidad continuaron y continúan hoy, atravesando los límites de los estados y dando forma a las relaciones y a los resultados del desarrollo a través y dentro de ellos.

En todo momento, durante la ascensión y caída de los estados y los sistemas estatales, el avance tecnológico y el desarrollo de las fuerzas productivas han sido impulsados y modelados, no por naciones, sino por clases locales y translocales que participan en el intercambio de tecnología, instituciones, ideas culturales, valores y otros productos simbólicos. Los valores, las prácticas de consumo y las innovaciones se difundieron, no a través de amplios frentes, sino a lo largo de las rutas de contacto, y estas dieron forma a la dirección del cambio social a través de grandes áreas de manera muy similar.” (pp. 8-9)

21 "Desde 1950, de 15 a 20 títulos con la palabra difusión aparecen cada década hasta la de 1990, cuando el número aumenta a 37". (Elkins y Simmons, 2005, p. 36). 
Anderson (1993), sin duda, ofrece una de las propuestas teóricas más conocidas. Aunque no define sistemáticamente el concepto de modularidad (el equivalente a "difusión"), este ocupa un lugar central en su propuesta. Anderson toma de Benjamin (2004) la noción de "tiempo homogéneo y vacío"; una nueva concepción del tiempo que se produjo gracias al capitalismo basado en el medio escrito (print capitalism), y que generó como resultados: a) campos unificados de intercambio y comunicación, b) una fijeza del lenguaje que permitió concepciones trans-históricas de la nación como un ente natural y eterno, y c) un orden jerárquico de "lenguajes del poder" que reconfiguró el terreno de la lucha política. Así, diversos actores, separados físicamente y sin conocimiento el uno del otro, fueron puestos colectivamente sobre un espacio nacional singular y dentro de un tiempo colectivo unitario. Surgió de esta manera, según Anderson, la idea de un nacionalismo modular, que se define como aquel capaz de ser trasplantado.

En la idea de modularidad de Anderson está implícita la de path-dependency ${ }^{22}$ (es decir, que los actos y decisiones del pasado condicionan o influyen en los actos y decisiones del presente): para mediados del siglo XIX la idea de un estado nacional independiente estaba ya disponible para ser "pirateado", pero debido a que era un modelo nuevo, impuso ciertos estándares, de los cuales no se permitían desviaciones muy marcadas. Los nacionalismos del siglo XX se presentan también con un carácter modular y path-dependent: se adoptan modelos educativos de los "nacionalismos oficiales", el sistema de partidos y elecciones y celebraciones culturales del nacionalismo popular europeo del siglo XIX, así como la idea ciudadano-republicana surgida en las Américas.

El enfoque de Anderson puede ser complementado con otras teorías, como la de Halperin, de modo que la categoría de modularidad -entendida como un proceso de mimesis path-dependent y de trasplante- pueda ser de utilidad, mutatis mutandis, para analizar la difusión de modelos culturales; tanto la difusión ligada al estado (de sistemas educativos o de rutinas administrativas, por ejemplo) como la ligada a procesos no estatales (gustos y preferencias de consumo de las élites translocales, por ejemplo), vincula, a la vez, los enfoques estructuralistas con los enfoques de corte subjetivista (culturales).

La relación de teorías como la de Halperin con teorías como la de Anderson es posible debido a la relación entre difusión y redes: "El aspecto de la difusión que más intriga a los sociólogos es la oportunidad que ella ofrece para un análisis de redes (...)" (Strang y Meyer, 1993) y, efectivamente, no parece posible difusión alguna sin un grado mínimo de relación entre los actores ${ }^{23}$. La modularidad misma puede ser explicada por la existencia de procesos y redes locales, translocales y globales.

Al respecto, puede ser útil considerar la propuesta teórica de Meyer, Boli, Thomas y Ramírez (1997), quienes. basados en el neoinstitucionalismo sociológico de Stanford, utilizan el concepto "sociedad mundial" para analizar el estado-nación como una institución construida por procesos culturales y asociativos mundiales, a partir de los cuales identifican: a) las propiedades del estado-

22 La idea de fondo es que ciertas decisiones sobre instituciones, tecnologías y el entorno construido pueden poner en marcha marcos referenciales que parecen adquirir vida propia; a medida que más capital social, político y económico está ligado con estos marcos de referencia, estos ejercen una mayor presión sobre la sociedad, lo que los hace cada vez más difíciles de cambiar. La teoría de path-dependency ha sido muy utilizada en Economía, especialmente la evolutiva de Nelson y Winter (1982).

23 A este respecto, como ejemplo, es de utilidad el estudio de Kaufman y Patterson (2005) sobre la difusión de prácticas culturales, centrado en la difusión internacional del cricket. Destacan el papel que cumplen las élites en la difusión de prácticas culturales: "Nuestra explicación se basa (...) en dos factores principales: primero, el grado en el que las élites eligen o apropiarse del juego y disuadir a otros de participar o promoverlo activamente en toda la población con propósitos hegemónicos; y segundo, el grado en el cual el juego fue 'popularizado' por empresarios culturales en busca de obtener y mantener espectadores y atletas interesados en el deporte. Ambos resultados están relacionados con la naturaleza de las jerarquías de status en estas diferentes sociedades y con la acción de las élites y empresarios en la formación del valor cultural del juego (...) la difusión de prácticas culturales pueden ser promovidas o desalentadas por intermediarios con el poder para dar forma al sentido cultural y la accesibilidad institucional de tales prácticas.” (p. 82) 
nación que resultan de su construcción impulsada exógenamente, b) los procesos por los cuales la cultura racionalista mundial afecta a los estados-nación, c) las características de la sociedad mundial que intensifican el impacto de la cultura global en los estados y sociedades nacionales (incluyendo las condiciones que favorecen la difusión de modelos mundiales, la expansión de asociaciones de nivel mundial y la autoridad racionalizada científica y profesional), d) las características dinámicas de la cultura y la sociedad mundiales que generan expansión, conflicto y cambio, entre ellas especialmente la no estatalidad (statelessness) de la sociedad mundial, la legitimación de múltiples niveles de actores racionalizados, y las inconsistencias y contradicciones internas. Meyer, Boli, Thomas y Ramírez (1997) afirman:

La operación de la sociedad mundial a través de peculiares procesos culturales y asociativos depende en gran medida de su no estatalidad. El carácter casi feudal de la parcelada soberanía legal-racional en el mundo tiene el resultado aparentemente paradójico de disminuir la importancia causal de las jerarquías organizadas de poder e intereses, celebradas en la mayoría de las teorías "realistas" de las ciencias sociales. La no estatalidad de la sociedad mundial también explica, en buena medida, la falta de atención de las ciencias sociales a la coherencia e impacto de las propiedades culturales y asociativas de la sociedad mundial (...) las ciencias sociales son más que reticentes a reconocer patrones de influencia y conformidad que no pueden explicarse solo como una cuestión de relaciones de poder o racionalidad funcional. (p. 145)

Por su parte, Strang y Meyer (1993), también desde la perspectiva del neoinstitucionalismo de Stanford, consideran la difusión dentro del marco cultural hegemónico representado por la modernidad, en la que se produce un isomorfismo ritualizado; esto es, se considera a los diferentes actores (sean estados, organizaciones o individuos) como homogéneos -omitiendo o desconociendo sus verdaderas diferencias- y, por lo tanto, susceptibles del mismo tratamiento teórico y práctico. Las prácticas y las instituciones, las formas y los contenidos "modernos", entonces, no son cuestionados, dado que los diferentes actores, se asume, son formalmente iguales, buscan los mismos fines y usan los mismos medios. El concepto de isomorfismo ritualizado es útil para comprender los procesos de difusión que se producen en la educación, tanto en los proyectos públicos como en los de agentes privados ${ }^{24}$.

Esta hegemonía cultural, si aplicamos las ideas de Halperin (2007), no proviene de un estadonación específico, sino que es sistémica. Existe un paralelismo entre la idea de isomorfismo ritualizado y la idea de ocultamiento a que se refiere Halperin (2007): "Las instituciones nacionales ligan la masa de la población local a un delimitado ámbito político y cultural, el cual, sin embargo,

\footnotetext{
"Las teorías modernas abogan por un orden moral más universalista, un análisis más científico y estandarizado de la naturaleza y de las relaciones entre medios y fines, y una visión más ahistórica de la naturaleza humana y la sociedad. La construcción de los actores en torno a estos conceptos los hace más similares, en formas fáciles de percibir y comunicar.

Desde este punto de vista, es comprensible la rapidez de los flujos entre actores sociales contemporáneos. Después de todo, tienen los mismos legítimos propósitos, de modo que son susceptibles de las mismas demandas sociales. Dependen de las mismas tecnologías, legitimadas por los mismos fundamentos, por lo que los flujos de técnicas mejoradas pueden ser rápidos y poco constreñidos por las lealtades tradicionales. Y tienen relativamente las mismas concepciones científicas de los recursos básicos, definiciones notablemente similares de la naturaleza humana, la autoridad colectiva y el control social, lo que permite que las 'innovaciones' en estas áreas fluyan rápidamente.

En consecuencia, argumentamos que cuanto más organizadas están las sociedades como estados-nación (y no como grupos 'primordiales' religiosos o étnicos), más se difunden las estructuras sociales entre ellas. Dentro de los estados-nación, en la medida que la acción colectiva tiene lugar dentro de organizaciones formales racionalizadas, ellos devienen isomórficos unos en relación con otros y con las reglas tanto del estado-nación como de la sociedad mundial [world society]. Y en el nivel individual, el surgimiento de nociones expandidas y unificadas de ciudadanía, capacidad y valía moral (en resumen, la construcción cultural mundial de la 'calidad de actor'), conduce rápidamente a los individuos a adoptar actitudes y prácticas de los demás y de los centros nacionales y mundiales.” (Strang y Meyer, 1993, p. 501)
} 
es penetrado transversalmente por las clases translocales. Todo el aparato de la cultura nacional y de la ideología del estado-nación tiende a hacer invisible la existencia de una élite capitalista mercantilista transcontinental (y hoy enmascara al creciente capitalismo financiero internacional) y la interdependencia de los lugares de producción" (p. 9).

Se trata de que las verdaderas fuerzas motrices del sistema quedan ocultas, aunque están presentes y operantes y son las que posibilitan la difusión. Ese mundo reticulado, sometido a un marco cultural hegemónico y a un sistema de relaciones económicas globales dominadas por élites locales y translocales -cabe advertir-, no puede ser estudiado, en el plano histórico, solo mediante prosopografías, pues el concepto de redes aquí es más complicado, dada la complejidad misma del fenómeno.

El difusionismo opera de manera no explícita y normalmente pasa inadvertido, debido a los poderes simbólico y cultural del estado (en la acción política) o por la dependencia académica o el nacionalismo metodológico (en la investigación y la docencia). No ha sido diferente la experiencia en los sistemas educativos nacionales. El hecho de que las decisiones sobre el sistema educativo se tomen a un nivel nacional, no significa que no se estén reproduciendo patrones extraños a la propia realidad. Al respecto, Dale (2005) advierte:

a) [Aunque] las decisiones se siguen tomando a un nivel nacional no necesariamente implica que allí es donde se encuentra el poder sobre esas decisiones (debido a la operación, a otros niveles, de la definición de la agenda, la configuración de preferencias y el establecimiento de normas).

b) [Si bien] las formas existentes continúan, en apariencia, más o menos invariables, ello no cambia el hecho de que nuevas formas, localizadas en diferentes escalas, están llegando a existir al lado de ellas.

c) Las formas existentes no necesariamente tienen el mismo significado que previamente tuvieron (por ejemplo, las monarquías).

d) La naturaleza y la amplitud de las áreas a través de las cuales pueden surgir diferencias internacionales se están estrechando bajo la economía del conocimiento. (p. 122)

Ahora bien, cabe preguntarse, ¿tiene algo de malo "copiar" teorías, modelos y sistemas educativos? No es posible defender un aislacionismo, pues unos pueblos pueden aprender de otros. Un adecuado benchmarking ${ }^{25}$, crítico y académicamente no dependiente, puede ser de gran utilidad social y coadyuvar, como proponía Jantsch (1972), a la constante autorrenovación de la sociedad. El problema se presenta si se trata de un simple trasplante, producto de una mentalidad cautiva y del ocultamiento (no reconocimiento y falta de concienciación) de las fuerzas, actores, relaciones y procesos subyacentes.

\section{Nacionalismo metodológico}

La academia también ha sido parte del "ocultamiento", por medio de la adopción de teorías de la ciencia que la presentan como neutral y apolítica y por la adopción de una perspectiva de la realidad parcelada, es decir, dividida en disciplinas presentadas como ámbitos autónomos y con lenguajes calificados como inconmensurables.

25 Entendido como la comparación entre organizaciones para adoptar y adaptar, con un carácter estratégico, las mejores prácticas. 
Además, se han acogido supuestos metodológicos implícitos, dados como formas naturales de abordar la realidad social, de los cuales el más importante ha sido el considerar al estado-nación como la unidad de análisis -y de praxis- natural de todo fenómeno social (Berger, 2001). Cuando se elige otra escala, esta es presentada en términos infra o supranacionales, siempre tomando como referencia obligada al estado-nación. Las regiones son vistas, en consecuencia, como partes de la nación (en el mejor de los casos, como subnaciones) y las relaciones que desbordan al estado-nación, como relaciones entre estados-nación. Todas las relaciones sociales, incluyendo las identidades, quedaron de esa manera apresadas por el estrecho marco del estado-nación y, de ese modo, territorializadas en unidades discretas ${ }^{26}$. Así, el estado-nación llegó a considerarse como un elemento constitutivo de la modernidad capitalista.

El problema con el nacionalismo metodológico es tanto lo que muestra (de manera sesgada) como lo que deja de mostrar. Taylor (2000) ofrece un par de ejemplos. El primero lo presenta al comparar un libro escrito desde una perspectiva no estadocentrista (Bauman, 1998) y otro que incurre en estadocentrismo (Held, McGrew, Goldblatt y Perraton, 1999). Afirma Taylor que luego de un siglo en que operó una reducción de la polarización social, desde la década de 1970 nuevamente se ha incrementado, presenciándose un severo cambio en la distribución del ingreso y la riqueza; este cambio, considera Taylor, es el más importante rasgo de la globalización contemporánea. El libro de Bauman (1998, p. 70) cita un Reporte de las Naciones Unidas sobre Desarrollo Humano con el informe de que 358 multimillonarios globales tienen una riqueza combinada equivalente al ingreso de las 2.3 mil millones personas más pobres del planeta.

En resumen, las nuevas tecnologías han facilitado el potencial para una nueva redistribución hacia arriba para aquellos que dominan la 'riqueza global' y pueden demandar 'salarios globales'. Y los proyectos políticos de la nueva derecha (instigados por los gobiernos de la 'nueva izquierda', cuando y como sea necesario) han asegurado que la muy rica élite pueda, en efecto, hacer más dinero y más rápido que nunca antes”. (Taylor, 2000, p. 1109)

Esa situación es una verdadera transformación global crítica, pero el libro de Held et al. (1999), al enfocar su análisis en el estado, trata los efectos de la globalización en la distribución, en los debates sobre el estado de bienestar y sobre la desindustrialización en los países más ricos, de modo que "(...) el panorama global y el relacionado cambio histórico en el poder y la riqueza, simplemente no son parte de su argumento" (Taylor, 2000, p. 1109).

El segundo ejemplo ofrecido por Taylor (2000) es el siguiente:

"El caso clásico es la inversión extranjera directa (IED); es ampliamente usado en el libro de Held et al. (1999) incluso para describir 'el sistema financiero global'. Aunque describe flujos de capital 'privado', tales datos son agregados para devenir atributos de estados (o grupos de estados), que ‘envían' o 'reciben', con poco o ningún sentido empírico del sistema detrás de los flujos. La datos sobre IED en el libro de Held et al. y en otros muchos textos, proveen información invaluable sobre tendencias pero muy poca sobre redes". (p. 1109)

El nacionalismo metodológico, que informa a las ciencias sociales desde el siglo XIX, ha corrido paralelo, prima facie, con el proyecto de construcción y consolidación de los estados

26 El nacionalismo metodológico se basa en la falacia del todo; por ello, no deja de ser paradójico que haya encontrado en el individualismo metodológico un complemento frecuente. Sobre dicha falacia véase Salas (2006). 
nacionales. Pero va más allá: es el reflejo metodológico de un proceso económico y político mundial (primer polo) -es decir, el del capitalismo industrial-, que en un nivel local se construyó como un proyecto nacional (segundo polo), naturalizado mediante el poder simbólico del estado. Al respecto Brenner (1999) advierte: “(...) la epistemología del estadocentrismo no debe ser vista tanto como un 'reflejo fiel' de su contexto histórico-geográfico sino como la omisión del reconocimiento, inducida estatalmente, de ese contexto" (p. 49), pues por un lado la compresión de los procesos espacio-temporales se vio intensificada en conjunción con la segunda revolución industrial, la expansión global de la economía y la era de un fuerte imperialismo; por otro lado, esta extensión y aceleración del capitalismo se basó en la construcción de configuraciones territoriales de gran escala, especialmente, las infraestructuras de producción, transporte y comunicación de las principales ciudades industriales y los sistemas institucionales y regulatorios, altamente burocratizados, de los estados territoriales. No obstante, manifiesta Brenner (1999), “(...) los modos de análisis estadocéntricos se enfocan solamente en un polo de esta dialéctica (...) el de fijeza territorial, incorporado en la forma territorializada del estado" (p. 49), obviando así los procesos -principalmente globales o locales- no reductibles a una escala estatal o interestatal (entendida esta como mera y exclusiva relación entre estados). La epistemología estadocéntrica realiza, entonces, un doble ocultamiento: a lo externo del estado-nación (procesos, flujos, actores y redes globalesglobales, globales-locales) y a lo interno del estado-nación (procesos, flujos, actores y redes localeslocales, locales-globales), al utilizar una escala sumamente limitada.

Hay que considerar, además, el poder simbólico del estado, que Loveman (2005), basada en Bourdieu, define como "(...) la capacidad para que se asuma como natural, inevitable, y por lo tanto apolítico, lo que es un producto de la lucha histórica y la invención humana” (p. 1655). El estado opera por medio de rutinas administrativas que, al recibir reconocimiento, se legitiman a sí mismas y a su vez, al estado; las personas las asumen entonces como el orden natural de la vida. El poder simbólico "(...) no es simplemente el poder de poner las reglas del juego, sino además el poder para 'enmarcar' el juego mismo, estableciendo las prácticas, categorías y esquemas cognitivos por medio de los cuales el juego es entendido y experimentado." (Loveman, 2005, p. 1656). Así, tal realidad institucional deviene naturalizada y asumida como "lo dado". Esto tiene como consecuencia que cada vez sea más difícil pensar y actuar fuera del marco conceptual y pragmático del estado. El poder simbólico se caracteriza por no ser visible, su fortaleza estriba en no ser percibido como presente; se trata de una función formal-legitimadora, no de contenidos específicos. Se diferencia del poder cultural en que este se ha entendido principalmente como ideología, la cual sí alude a unos determinados contenidos y cumple, por tanto, una función sustantivo-legitimadora, por medio de mensajes culturales y símbolos específicos, así como de creencias particulares (tómese por caso la invención de la nacionalidad como una forma de crear e impulsar la lealtad de las personas, categorizadas como ciudadanos). El poder cultural presupone un grado mínimo de poder simbólico; este, en consecuencia, es un metapoder.

Para comprender mejor los poderes simbólico y cultural del estado-nación, cabe retomar el concepto de modularidad, propuesto por Anderson (1993) y reelaborado de una forma más explícita por Goswami (2002). Una de las dimensiones constitutivas de la modularidad del estado es su durabilidad, que para Goswami se manifiesta en tres aspectos: a) la forma modular de la nación subyace a una serie de prácticas e instituciones que ha generado y que estructuran las matrices de la vida social y política, entre ellas: las instituciones asociadas con las economías nacionales (regímenes de planificación económica, sistemas nacionales fiscales y de bienestar, moneda nacional, tarifas, cuotas de importación, banca nacional, deuda nacional), la construcción de campos culturales (idiomas oficiales, instituciones educativas, museos, sistematización de tradiciones folclóricas, la formación 
de esferas públicas nacionales y tradiciones literarias), instituciones que regulan la pertenencia política y cultural y la movilidad territorial (ciudadanía, pasaportes, fronteras), la creación de particulares ambientes construidos que sirven como lugares espacio-temporales de la memoria colectiva mediada por el estado (capitales nacionales, monumentos conmemorativos nacionales); b) la forma de la nación es omnipresente en una serie de instituciones políticas y económicas, y de categorías de pensamiento y acción: el estado-nación es la forma política dominante a escala global y las categorías epistemológicas nacionalistas calan los marcos interpretativos y las prácticas sociales, tanto en la vida cotidiana como en la esfera pública, articulando las identidades colectivas y los proyectos políticos; c) La durabilidad y profundidad de la forma de la nación se deriva de su status reificado y socialmente producido: es decir, a partir de los modos en que muchas de las prácticas, instituciones y categorías conceptuales, asociadas con el estado-nación y el nacionalismo, se han transformado en una segunda naturaleza o han pasado a considerarse como naturales.

La superación del nacionalismo metodológico se ve facilitada por la propia dinámica de la actual fase de la globalización, dado que las ciencias sociales, estructuradas en compartimientos estancos y con supuestos reduccionistas, se han visto imposibilitadas de explicar diversos procesos para los que los métodos y categorías tradicionales no estaban preparados. "La globalización plantea un desafío para el trabajo teórico sobre el estado", ha escrito Robinson (2001, p. 190). Uno de esos procesos es la misma reestructuración del estado-nación y del sistema interestatal westphaliano (Robinson, 2001); Brenner (1999). Se considera ese "re-escalamiento" (o salto de las escalas) de la territorialidad "como la differentia specifica del ciclo actual de la globalización" (p. 53). Tal reescalamiento tiene significativas consecuencias epistemológicas; como afirman Wimmer y Glick (2002):

Sólo ahora que los estados-nación han perdido algo de su poder frente a las corporaciones transnacionales y organizaciones supranacionales, podemos ver retrospectivamente la forma que ha adoptado la modernidad durante los últimos 200 años. Ella fue lanzada dentro de la caja de hierro de los estados nacionalizados, los que confinaron y limitaron nuestra propia capacidad analítica (...) [Hemos descubierto] cuán transnacional ha sido el mundo siempre, incluso en los días de apogeo cuando el estado-nación acotaba y ligaba la mayor parte de los procesos sociales. Más que un resultado reciente de la globalización, el transnacionalismo se muestra como una constante de la vida moderna, oculta a la vista del nacionalismo metodológico. (p. 302)

Entre los recursos a los que se ha acudido en un intento por superar el nacionalismo metodológico está el método comparado, el cual, por sí mismo, no garantiza que se eviten sus sesgos. Si lo que se compara son datos generados "nacionalmente", el método comparado ocultará a actores, redes, procesos, intereses, fuerzas, grados de poder y agendas que operan en niveles y escalas distintos al nacional. Weber (2007) advierte que la globalización y el desarrollo han sido conceptualizados en términos ahistóricos; pone como ejemplo las estrategias de reducción de la pobreza (los objetivos de desarrollo del milenio y los documentos de estrategia de lucha contra la pobreza), definidas globalmente, pero destinadas a ser implementadas dentro de los dominios nacionales, como estrategias de desarrollo nacional. El método comparado formal corrobora dicho enfoque ahistórico; por ello, dicho método, afirma Weber, debe ser reevaluado críticamente, no sólo para rectificar un problema metodológico, sino también para exponer las políticas de elección metodológica, pues “(...) el método comparado formal se fundamenta en delimitaciones temporales y espaciales que reproducen un marco analítico particularmente problemático, con importantes implicaciones políticas, y que 
oscurece las dimensiones sociales, globalmente constituidas, de las luchas por el reconocimiento y la redistribución" (Weber, 2007, p. 559).

Una ciencia y una educación transdisciplinarias serán capaces de abordar el estudio de la realidad con una perspectiva totalizadora, quebrando de ese modo el patrón estadocentrista hasta ahora vigente y que limita, sin duda alguna, la perspectiva de totalidad de los diversos y complejos procesos humanos, que operan en múltiples escalas de espacio y tiempo ${ }^{27}$. El proceso educativo debe también repensarse en el nuevo escenario pos-internacional ${ }^{28}$ (transestatal, en las categorías de Taylor, 2000) para responder, especialmente, a aquellas situaciones humanas de desigualdad e injusticia que el modelo tradicional -disciplinario, eurocentrista y estadocentrista- ha dejado en la sombra, cuando no del todo en el olvido ${ }^{29}$.

\section{El papel de la universidad}

Finalmente, concluimos por donde debimos haber empezado: el papel social de la universidad. En el momento actual, cuando se aborda el tema de las distintas formas de relación entre disciplinas, generalmente se hace referencia a tres categorías: multidisciplinariedad, interdisciplinariedad y transdisciplinariedad ${ }^{30}$. Pero los enfoques más recientes incluyen a no académicos en el trabajo transdisciplinario, lo cual desborda los límites de la organización universitaria misma ${ }^{31}$. Sin embargo, ya en los inicios del uso del concepto transdisciplinariedad, a principios de la década

27 Totalidad, entendida como una construcción y no como un universal: "Es decir, que la percepción (valoración) del "Todo" depende, esencialmente, de un acuerdo histórico-social al respecto. No se trata de que existan entidades universales, tal y como postula el realista platónico en la filosofía y el holista en las ciencias sociales, sino que esas entidades (convencionales) son construcciones de individuos determinados, en épocas históricas también determinadas" (Salas, 2006, p. 48). Que la totalidad es un constructo, es algo que ya estaba claro desde tiempos de Kant, cuando este colocaba la categoría de totalidad junto a las de unidad y pluralidad.

28 Cabe señalar que existe la tendencia a considerar que la globalización está conduciendo a la desaparición del estado-nación. En realidad solo se está transformando para adaptarse a la nueva situación; de paso es un agente facilitador, de no poco peso, en el proceso de la globalización. "El sistema del estado-nación no está siendo destruido sino transformado e incorporado por medio del proceso de la globalización en la estructura emergente más amplia de un estado transnacional", afirma Robinson (2001, p. 192; véase también sobre este tema Brenner, 1999). Green (1997) concuerda en que el estado no está desapareciendo y considera que más bien la nueva realidad global de interdependencia económica y social ha fomentado tantos nuevos papeles para el estado como le ha restado otros antiguos.

29 Sobre el carácter excluyente de la ciencia "tradicional", véase por ejemplo Harding (1991), en relación con la discriminación de género.

30 Denemark (1999) por ejemplo se refiere a ellas de la siguiente manera:

"[Multidisciplinariedad]: “(...) académicos de diferentes disciplinas se unen para trabajar en un problema. Aunque de utilidad, cada perspectiva aplica diferentes ópticas, plantea preguntas diferentes y utiliza un vocabulario distinto. Los académicos, en un nivel individual, obtienen conocimiento intuitivo de sus colegas y pueden llegar a entender mejor el fenómeno en cuestión, pero los participantes no serán capaces de evaluar las aportaciones de sus colegas o de actuar independientemente en el estudio de fenómenos subsecuentes.

(...) [Interdisciplinariedad]: Los académicos que realizan un trabajo interdisciplinario dominan las herramientas analíticas de otra disciplina y las aplican al estudio de una cuestión de interés. De aquí que un individuo considere 'ambos' tipos de atributos como mostrados por un fenómeno dado. El trabajo interdisciplinario es difícil, retributivo e importante, pero aún aborda el fenómeno como si tuviera dos (o quizá más) facetas separadas que deben ser consideradas como interactivas.

(...) [Transdisciplinariedad]: Los académicos que realizan este tipo de trabajo a menudo comienzan con un interés por algunos fenómenos complejos que no pueden ser aprehendidos sino con un conjunto de varias herramientas analíticas compartidas. El foco aquí no está en la interacción de los análisis por separado sino en obtener un entendimiento del complejo -y a menudo, de gran escala- proceso social en sí mismo. Un amplio proyecto transdisciplinario podría incluir a personas con diferentes formaciones disciplinarias originales, pero la ruptura de las fronteras que separan a las disciplinas es el interés principal.” (p. 53)

31 Según Graybill, Dooling, Shandas, Withey, Greve y Simon. (2006) el trabajo multidisciplinario supone que investigadores de dos o más disciplinas trabajan de manera colaborativa en un problema común, sin modificar los enfoques disciplinarios ni desarrollar marcos conceptuales sintéticos; un enfoque interdisciplinario supone el uso de un marco conceptual innovativo para sintetizar y modificar dos o más enfoques disciplinarios para tratar un problema de investigación; un enfoque transdisciplinario supone a profesionales no académicos trabajando con académicos para identificar, investigar y desarrollar soluciones a problemas del mundo real. 
de 1970, se habían hecho propuestas sumamente interesantes, entre las que destaca la de Jantsch (1972). Para dicho autor “(...) la tradicional separación del conocimiento y su transferencia en una variedad de disciplinas se ha desarrollado desde otro punto de vista, a saber, que es posible obtener una explicación mecánica del mundo como él es, al situar la observación empírica en un contexto lógico" (Jantsch, 1972, p. 13). Jantsch propone, en cambio, un punto de vista antropomórfico, que por definición no puede ser objetivo, pues va dirigido a mejorar el sistema de la sociedad humana y, por tanto, desde una perspectiva subjetiva, apunta a determinados propósitos. Se trata de un modelo de la acción humana -concepto quizá tomado de von Mises (1949, p. 10) - y no de un modelo mecánico. "La disciplinariedad en la ciencia es, en principio, esencialmente estática, lo que deja de tener sentido si se considera en el marco de un sistema con propósitos" (Jantsch, 1972, p. 13).

Para Jantsch, la reforma de la universidad no debe empezar enfocándose en problemas tales como los diferentes tipos operativos de universidad, la innovación en los enfoques didácticos o la reforma curricular. Antes que los aspectos tácticos y estratégicos, debe debatirse y explicitarse la dimensión política, esto es, el papel de la universidad como una institución de la sociedad, el cual -sostiene basándose en Gardner- "(...) puede ser visto en el decisivo papel que juega en el mejoramiento de la capacidad de la sociedad para su continua autorrenovación" (Jantsch, 1972, p. 12). Acepta expresamente que esto significa que la universidad devenga en una institución política, en su más amplio sentido. Así, las disciplinas, sus límites, comunicaciones y relaciones, vendrían a depender de la orientación normativa de la educación y de la innovación y no de "un sistema $a$ priori de la ciencia". Adoptar el nuevo sistema de la universidad supone un abordaje diferente de las disciplinas y requiere, necesariamente, la transdisciplinariedad, que debe ser entendida como un concepto teleológico y normativo, es decir, supone definir y explicitar fines y valores a la organización de la ciencia.

Jantsch utiliza seis categorías, que define de la siguiente manera: a) disciplinariedad: especialización en aislamiento, b) multidisciplinariedad: una variedad de disciplinas que se ofrecen simultáneamente, pero sin explicitar posibles relaciones entre ellas, c) pluridisciplinariedad: la yuxtaposición de varias disciplinas, generalmente del mismo nivel jerárquico (empírico o pragmático) agrupadas para mejorar las relaciones entre ellas, d) traversdisciplinariedad (crossdisciplinarity): el sistema axiomático de una disciplina se impone a otras disciplinas en el mismo nivel jerárquico, creando una rígida polarización hacia un concepto monodisciplinario específico ${ }^{32}$, e) interdisciplinariedad: un sistema axiomático común para un grupo de disciplinas relacionadas, se define a un nivel jerárquico más alto e introduce un sentido de propósito, f) transdisciplinariedad: se produce la coordinación, en todos los niveles, de todas las disciplinas e interdisciplinas del sistema de educación e innovación, sobre la base de un sistema axiomático generalizado y de un modelo epistemológico emergente, cuya orientación se produce por medio de los fines de todo el sistema.

Es claro que, para Jantsch, la transdisciplinariedad no puede pensarse como un sistema de ciencia y educación libre de valores; al contrario, son estos los que orientan a todo el sistema y, si varían, todo el sistema, consecuentemente, se modifica. Se trata, en última instancia, de definir y poner en juego unos valores y normas para el sistema de educación e innovación que concretan una política para la humanidad (“a policy for mankind").

\footnotetext{
Un ejemplo de crossdisciplinarity es el análisis económico del Derecho o bien, el estudio de la ciencia y el conocimiento desde una perspectiva puramente económica, como hace la Economía evolucionista (de autores como Nelson, Winter y Dosi), aun cuando pretende superar en esto a la Economía neoclásica (que aborda el conocimiento científico como una variable exógena) y sugiere el diálogo con otras disciplinas como la Historia, la Sociología o la Filosofía (véase Barge-Gil y Modrego, 2009). Otro ejemplo es la contienda entre la Nueva Economía Institucional y la Nueva Sociología Económica.
} 
Lo interesante de la propuesta de Jantsch es que, a diferencia de otras propuestas, no deriva la transdisciplinariedad de ninguna teoría ontológica o epistemológica, sino política, desde la cual aborda aspectos normativos, teleológicos y prácticos, es decir, relativos a la acción humana y a la sociedad.

Con base en los aportes de Jantsch, cabe afirmar que el tema de la transdisciplinariedad apunta directamente a decisiones políticas, antes que - pero también- cognitivas. La dimensión cognitiva, entonces, es un medio para lograr unos determinados fines políticos, los cuales se traducen en metateorías, teorías generales y métodos, los que también son factores políticos, no solo en el sentido apuntado más arriba, relacionado con luchas a lo interno de las academias (enfrentamiento entre grupos y culturas de las academias, contiendas retóricas por autoridad y legitimación, competencia por recursos), sino principalmente porque, por medio de ellos, se coadyuva a construir la realidad y se legitima o cuestiona el orden social, pues "el conocimiento y la sociedad son inseparables ${ }^{33}$ " (Barnes, 1990, p. 218). Es en el orden político donde se define -aún de manera tácita- el papel de la universidad en la globalización.

En algunos planteamientos instrumentales de la educación, esta debe servir a los propósitos de formar el capital humano que impulsará el desarrollo económico. La elección en primera instancia no es entre dicho uso instrumental o el ideal humanístico, sino entre diversas opciones políticas ${ }^{34}$.

\section{Conclusiones}

1. La ciencia es una construcción histórica. La elección de sus teorías y métodos está influida por el contexto histórico en que se producen y, en consecuencia, refleja, a su vez, una elección política. No existe ciencia autónoma de la realidad social en que se produce, ni políticamente neutra.

2. La actual estructuración de la ciencia en disciplinas obedece a las condiciones de su surgimiento en el capitalismo industrial del siglo XIX y ha dominado el panorama académico hasta hace unas pocas décadas, cuando los mismos procesos de la globalización la han puesto en entredicho. Surge, entonces, la necesidad de la emergencia de nuevas formas de concebir la organización universitaria y la ciencia, que superen la estructura fraccionaria disciplinaria.

3. La división internacional del trabajo y el mismo orden del capitalismo industrial y postindustrial han producido relaciones de dependencia académica a escala mundial. Las regiones dependientes académicamente generalmente limitan su producción a los proyectos de investigación empírica y no generan sus propias teorías. Una actitud crítica que vaya más allá de meras respuestas tecnocráticas es necesaria para lograr la independencia académica, especialmente en las regiones más pobres, a las que se impone una agenda transnacional -frecuentemente invisibilizada por los propios esquemas epistemológicos-, en prácticamente todos los campos, entre ellos la organización del sistema educativo.

4. Uno de los supuestos metodológicos más arraigados en la actual estructura de las ciencias es el nacionalismo metodológico, que asume como unidad natural de análisis y de praxis el

\footnotetext{
"Para unos seres humanos dados, en un ambiente determinado, cualquier cambio en la distribución de conocimiento implica un cambio en la distribución de poderes. No se trata de que una cosa precipite a la otra, o sea su causa, o que haga a la otra inevitable; se trata más bien de que una cosa equivale a la otra. Al hablar de conocimiento y de poder nos estamos refiriendo a una sola y misma cosa. Una sociedad es un conjunto ordenado de poderes, en virtud de que es una distribución de conocimiento" (Barnes, 1990, p. 216). Véase también Barnes (1974).

34 Afirmaba Cox para el caso de los países no desarrollados en 1968: "Considerar el desarrollo de recursos humanos (educación y mano de obra) como la variable independiente y el crecimiento económico como la variable dependiente podría representar una visión incompleta y posiblemente falsa del proceso. Ambas requieren ser consideradas en una relación de dependencia de la política y el poder" (p. 311). Esta afirmación no parece haber perdido vigencia en el contexto actual.
} 
estado-nación, con lo cual han quedado ocultos muchos procesos de la realidad. Su superación es uno de los retos para la ciencia que se produzca en el siglo XXI.

5. La nueva organización universitaria debe pensarse en su relación con la sociedad, no como algo externo a esta, sino como una de sus partes constitutivas. Esto significa tomar conciencia del papel de la educación y de la misma universidad, lo que requiere la toma de decisiones en el ámbito político, como estadio previo a cualquier reforma organizativa y curricular.

6. Las propuestas transdisciplinarias deben servir para impulsar la reforma de la universidad del siglo XXI, con una actitud crítica y consciente del papel que juegan la ciencia y la educación en la conformación del orden de la sociedad a escala planetaria, y debe tomar en cuenta, especialmente, los intereses de aquellos que han quedado ocultos por el modelo tradicional de las ciencias.

\section{Referencias bibliográficas}

Alatas, S. F. (2003, Noviembre). Academic Dependency and the Global Division of Labour in the Social Sciences [La dependencia académica y la división global del trabajo en las ciencias sociales]. Current Sociology, 51 (6), 599-613. Doi: 10.1177/00113921030516003

Alatas, S. F. (2004). The Meaning of Alternative Discourses: Illustrations from Southeast Asia. En S. Ravi, M. Rutten, y B. Goh (Eds.). Asia in Europe. Europe in Asia (pp. 57-78). Leiden y Singapur: International Institute for Asian Studies e Institute of Southeast Asian Studies.

Anderson, B. (1993). Comunidades imaginadas. Reflexiones sobre el origen y difusión del nacionalismo. México: Fondo de Cultura Económica.

Angelides, A. (2004, Julio). The Last Collapse? An Essay Review of Hilary Putnam's “The Collapse of the Fact/Value Dichotomy and Other Essays" El colapso pasado? Una revision de ensayos de Hillary Putnam es el colapso de la dicotomía hecho / valor y otros ensayos. Philosophy of Science, 71(3), 402-411.

Austin, A. E. (1990). Faculty Cultures, Faculty Values. En W. G. Tierney (Ed.), Assessing Academic Climates and Cultures (pp. 61-74). San Francisco: Jossey-Bass.

Bárcenas, R. (2002, Mayo-Agosto). Contexto de descubrimiento y contexto de justificación: un problema filosófico en la investigación científica. Acta Universitaria, 12(2), 48-57.

Barge-Gil, A. y Modrego, A. (2009, Julio-Agosto). Ciencia y economía. Arbor Ciencia, pensamiento y cultura, 185(738), 757-766. doi:10.3989/arbor.2009.i738

Barnes, B. (1974). Scientific Knowledge and Sociological Theory. Londres: Routledge y Kegan Paul.

Barnes, B. (1990). La naturaleza del poder. Barcelona: Pomares-Corredera.

Bauman, Z. (1998). Globalization: The Human Consequences. Cambridge: Polity Press. 
Bazerman, Ch. (1988). Shaping Written Knowledge: The Genre and Activity of the Experimental Article in Science. Madison: University of Wisconsin Press.

Benjamin, W. (2004). Tesis sobre la historia y otros fragmentos. México: Contrahistorias.

Berger, M. T. (2001, December). The Nation-State and the Challenge of Global Capitalism [El Estado-nación y el desafío del capitalismo global]. Third World Quarterly, 22 (6), 889-907. Doi: 10.1080/01436590120099704

Blaug, M. (1992). The Methodology of Economics. Or how economists explain. Nueva York: Cambridge University Press.

Blaut, J. M. (1987, Marzo). Diffusionism: A Uniformitarian Critique [Difusionismo: una crítica de la homogeneización]. Annals of the Association of American Geographers, 77 (1), 30-47. Doi: 10.1111/j.1467-8306.1987.tb00143.x

Bloor, D. (1982). Formal and Informal Thought. En B. Barnes y D. Edge. (Eds.), Science in context (pp. 117-124). Milton Keynes: Open University Press.

Bögenhold, D. (2008). Economics, Sociology, History: Notes on Their Loss of Unity, Their Need for Re-integration and the Current Relevance of the Controversy between Carl Menger and Gustav Schmoller [Economía, sociología, historia: notas sobre la pérdida de su unidad, la necesidad de su reintegración y la relevancia actual de la controversia entre Carl Menger y Gustav Schmoller]. Forum for Social Economics, 37 (2), 85-101. Doi: 10.1007/s12143-0079005-2

Bourdieu, P. (2003). El oficio de científico. Ciencia de la ciencia y reflexividad. Barcelona: Anagrama.

Bowen, J. (1992). Historia de la educación occidental. El Occidente moderno. Europa y el Nuevo Mundo (siglos XVII-XX) (tomo III). Barcelona: Herder.

Brenner, N. (1999). Beyond State-Centrism? Space, Territoriality, and Geographical Scale in Globalization Studies [¿Más allá del estadocentrismo? Espacio, territorialidad y escala geográfica en los estudios sobre la globalización]. Theory and Society, 28 (1), 39-78. Doi: 10.1023/A:1006996806674

Brunet, I. y Pastor , I. (2003). Ciencia, sociedad y economía. Madrid: Fundamentos.

Bunge, M. (2005). Diccionario de Filosofía. México, D. F.: Siglo XXI.

Cameron, K. y Ettington, D. (1988). The Conceptual Foundations of Organizational Culture. En J. Smart (Ed.), Higher Education: Handbook of Theory and Research (Vol. 4, pp. 356-396). New York: Agathon. 
Charle, Ch., Schriewer, J. y Wagner, P. (2004). Editors' Preface. En Ch. Charle, J. Schriewer y P. Wagner (Eds.). Transnational Intellectual Networks. Forms of Academic Knowledge and the Search for Cultural Identities (pp. 9-14). Frankfurt del Main: Campus.

Clark, B. (1983). The Higher Education System: Academic Organization in Cross-National Perspective. Berkeley: University of California Press.

Cox, R. W. (1968). Education for Development [Educación para el desarrollo]. International Organization, 22(1), 310-331.

Cox, R. W. (1996). Approaches to World Order. Nueva York: Cambridge University Press.

Dale, R. (2005, Mayo). Globalisation, Knowledge Economy and Comparative Education [Globalización, conocimiento, economía y educación comparada]. Comparative Education, 41(2), 117-149. Doi: 10.1080/03050060500150906

Denemark, R. A. (1999, Summer). World System History: From Traditional International Politics to the Study of Global Relations [Historia del sistema-mundo: de la política internacional tradicional al estudio de las relaciones globales]. International Studies Review, 1 (2), 43-75. Doi: $10.1111 / 1521-9488.00155$

Dill, D. D. (1991). The Management of Academic Culture: Notes on the Management of Meaning and Social Integration. En J. L. Bess (Ed.). Foundations of American Higher Education (pp. 567-579). Needham Heights, MA: Ginn Press.

Drori, G. S., Meyer, J. W., Ramírez, F. O. y Schofer, E. (2006). La ciencia en la política mundial moderna. Institucionalización y globalización. Barcelona: Pomares.

Eder, K. (2008). Las sociedades aprenden y aún así el mundo es difícil de cambiar. Revista de Sociología [de la Universidad de Chile], (22), 11-35.

Elkins, Z. Y Simmons, B. (2005). On Waves, Clusters, and Diffusion: A Conceptual Framework [Sobre olas, conglomerados y difusión: un marco conceptual]. Annals of the American Academy of Political and Social Science, 598 (1), 33-51.

Fernández, M., y Torres, C. (2009, Julio-Agosto). La ciencia como institución social: clásicos y modernos institucionalismos en la sociología de la ciencia. Arbor Ciencia, pensamiento y cultura, 185(738), 663-687. doi: 10.3989/arbor.2009.738n1045

Frickel, S. y Gross, N. (2005, Abril). A General Theory of Scientific/Intellectual Movements [Teoría general de los movimientos científicos e intelectuales]. American Sociological Review, 70(2), 204-232.

Friedman, M. (1953). The Methodology of Positive Economics. En M. Friedman (1953). Essays in Positive Economics (pp. 3-43). Chicago: University of Chicago Press. 
Frost, S. H. y Jean, P. M. (2003, Marzo-Abril). Bridging the Disciplines: Interdisciplinary Discourse and Faculty Scholarship [Tendiendo un puente entre las disciplinas: discurso interdisciplinario y la erudición del profesorado]. The Journal of Higher Education, 74(2), 119-149. Doi: 10.1353/ jhe.2003.0013

García-Bermejo, J. C. (2005). Conjeturas y modelos: acerca de K. Popper y la teoría económica. Energeia, 4(1-2), 117-156.

Goswami, M. (2002, Octubre). Rethinking the Modular Nation Form: Toward a Sociohistorical Conception of Nationalism [Repensando la forma modular de la nación: hacia una concepción sociohistórica del nacionalismo]. Comparative Studies in Society and History, 44(4), 770-799. Doi: 10.1017/S001041750200035X

Graybill, J. K., Dooling, S., Shandas, V., Withey, J., Greve, A. y Simon, G. L. (2006, Setiembre). A Rough Guide to Interdisciplinarity: Graduate Student Perspectives [Guía básica de la interdisciplinariedad: la perspectiva de los estudiantes de posgrado]. BioScience, 56(9), 757-763. doi:10.1641/0006-3568(2006)56[757:ARGTIG]2.0.CO;2

Green, A. (1997). Education, Globalization and the Nation State. Londres: Mcmillan.

Halperin, S. (2007, Diciembre). Reconceptualizando el desarrollo global: Re-Envisioning Global Development: Conceptual and Methodological Issues [Una nueva concepción del desarrollo global: cuestiones conceptuales y metodológicas]. Globalizations, 4(4), 543-558.

Harding, S. (1991). Whose Science? Whose Knowledge? Thinking from Women's Lives. Ithaca: Cornell University Press.

Held, D., McGrew, A., Goldblatt, D. y Perraton, J. (1999). Global Transformations: Politics, Economics and Culture. Cambridge: Polity Press.

Ibáñez, J. (2002). Poder y autoridad en las relaciones internacionales: el control del comercio electrónico en Internet. (Tesis doctoral). Universidad Pompeu Fabra, Barcelona, España.

Jantsch, E. (1972). Inter- and Transdisciplinary University: A Systems Approach to Education and Innovation [La Universidad inter y transdisciplinaria: un enfoque de sistemas sobre la educación y la innovación]. Higher Education, 1(1), 7-37.

Kaufman, J. y Patterson, O. (2005, Febrero). Cross-National Cultural Diffusion: The Global Spread of Cricket [Difusión cultural transnacional: la propagación global del cricket]. American Sociological Review, 70(1), 82-110.

Kobrin, S. J. (1985, Marzo). Diffusion as an Explanation of Oil Nationalization: Or the Domino Effect Rides Again [La difusión como una explicación de la nacionalización petrolera: o de nuevo el efecto dominó]. The Journal of Conflict Resolution, 29(1), 3-32. Doi: $10.1177 / 0022002785029001001$ 
Kuhn, T. S. (1962). The Structure of Scientific Revolutions. Chicago: University of Chicago Press.

Lamo de Espinoza, E., González, J. M. y Torres, C. (1994). La sociología del conocimiento y de la ciencia. Madrid: Alianza.

Loveman, M. (2005, Mayo). The Modern State and the Primitive Accumulation of Symbolic Power [El Estado moderno y la acumulación primitiva de poder simbólico]. American Journal of Sociology, 110(6), 1651-1683. Doi: 0002-9602/2005/11006-0003\$10.00

McCloskey, D. N. (1989). The Dismal Science and Mr. Burke. Economics as a Critical Theory. En H. W. Simons y T. Melia (Eds.). The Legacy of Kenneth Burke (pp. 99-114). Winconsin: University of Winconsin Press.

Menger, Carl (1976). Principles of Economics. Nueva York: New York University Press.

Merton, R. K. (1973). The Sociology of Science: Theoretical and Empirical Investigations. Chicago: University of Chicago Press.

Meyer, O. W., Boli, J., Thomas, G. M. y Ramírez, F. O. (1997, Julio). World Society and the NationState [La sociedad mundial y el Estado-nación]. The American Journal of Sociology, 103(1), 144-181.

Nelson, R. y Winter, S. (1982). An Evolutionary Theory of Economic Change. Londres: The Belknap Press of Harvard University.

Neufeld, M. (1993, Marzo). Reflexivity and International Relations Theory [Reflexividad y teoría de las Relaciones Internacionales]. Millenium: Journal of International Studies, 22(1), 53-76. Doi: 10.1177/03058298930220010501

O’Loughlin, J., Ward, M. D., Lofdahl, C. L., Cohen, J. S., Brown, D. S., Reilly, D., Gleditsch, K. S. y Shin, M. (1998, Diciembre). The Diffusion of Democracy, 1946-1994 [La difusión de la democracia, 1946-1994]. Annals of the Association of American Geographers, 88(4), 545-574. Doi: 10.1111/0004-5608.00112

Organización de las Naciones Unidas para la Educación, la Ciencia y la Cultura [UNESCO] e International Social Science Council [ISSC]. (2010). World Social Science Report. Knowledge Divides. París: autor.

Patnaik, P. (2005, Setiembre-Octubre). Education and Globalisation [Educación y globalización]. Social Scientist, 33(9/10), 100-111.

Peterson, M. W. y Spencer, M. G. (1990). Understanding Academic Culture and Climate. En W. G. Tierney (Ed.), Assessing Academic Climates and Cultures (pp. 3-18). San Francisco: Jossey-Bass. 
Polanyi, K. (1997 [1944]). La gran transformación. Crítica del liberalismo económico. Madrid: La Piqueta.

Putnam, H. (2002). The Collapse of the Fact/Value Dichotomy and Other Essays. Cambridge, MA: Harvard University Press.

Reichenbach, H. (1938). Experience and Prediction. Chicago: University of Chicago Press.

Robinson, W. I. (2001, Abril). Social Theory and Globalization: The Rise of a Transnational State [Teoría social y globalización: el surgimiento de un Estado transnacional]. Theory and Society, 30(2), 157-200.

Rousseau, D. y van der Veen, A. M. (2005, Octubre). The Emergence of a Shared Identity: An Agent-Based Computer Simulation of Idea Diffusion [La emergencia de una identidad compartida: una simulación computadorizada basada en el agente de la idea de difusión]. The Journal of Conflict Resolution, 49(5), 686-712. Doi: 10.1177/0022002705279336

Schriewer, J. y Keiner, E. (1997). Pautas de comunicación y tradiciones intelectuales en las ciencias de la educación: Francia y Alemania. Revista mexicana de investigación educativa, 2(3), 117148)

Simmons, B. A. y Elkins, Z. (2004). The Globalization of Liberalization: Policy Diffusion in the International Political Economy [La globalización de la liberalización: difusión de políticas en la Economía Política Internacional]. American Political Science Review, 98 (1), 171-189. Doi:10.1017/S0003055404001078

Salas, M. E. (2005). La explicación en las ciencias sociales: consideraciones intempestivas contra el dualismo metodológico en la teoría social. Reflexiones, 84(2), 51-60.

Salas, M. E. (2006). La falacia del todo: claves para la crítica del holismo metodológico en las ciencias sociales y jurídicas. Revista telemática de Filosofía del Derecho, (10), 33-52.

Sørensen, G. (1998). International Relations Theory after the Cold War. En T. Dunne, M. Cox y K. Booth (Eds.). The Eighty Years' Crisis: International Relations 1919-1999 (pp. 83-100). Cambridge, Reino Unido: Cambridge University Press.

Strang, D. y Meyer, J. W. (1993). Institutional Conditions for Diffusion [Las condiciones institucionales para la difusión]. Theory and Society, 22(4), 487-511. doi: 10.1007/BF00993595

Strange, S. (1996). The Retreat of the State. The Diffusion of Power in the World Economy. Cambridge, U. K.: Cambridge University Press.

Strange, S. (1997). Casino Capitalism. Manchester, U. K.: Manchester University Press.

Taylor, P. J. (2000, Junio). Embedded Statism and the Social Sciences 2: Geographies (and 
Metageographies) in Globalization [Estatismo inmerso y las ciencias sociales 2: geografías (y metageografías) en la globalización]. Environment and Planning A, 32(6), 1105-1114, Doi:10.1068/a32153.

Tierney, W. y Rhoads, R. (1994). Enhancing Promotion, Tenure, and Beyond: Faculty Socialization as a Cultural Process (ASHE-ERIC Higher Education Report $N^{\circ}$ 6). Washington, DC: Association for the Study of Higher Education.

Toma, J. D. (1997, Noviembre-Diciembre). Alternative Inquiry Paradigms, Faculty Cultures, and the Definition of Academic Lives [Paradigmas alternativos de investigación, culturas del profesorado y la definición de las vidas académicas]. The Journal of Higher Education, 68(6), 679-705.

Veblen, T. (1909, Noviembre). The limitations of Marginal Utility [Las limitaciones de la utilidad marginal].The Journal of Political Economy, 17(9), 620-636.

Veblen, T. (2007). The Theory of the Leisure Class. Nueva York: Cosimo.

Von Mises, L. (1949). Human Action: A Treatise on Economics. New Haven: Yale University Press.

Wagner, P. (2004). Introduction to Part I. En Ch. Charle, J. Schriewer y P. Wagner (Eds.). Transnational Intellectual Networks. Forms of Academic Knowledge and the Search for Cultural Identities (pp. 17-25). Frankfurt del Main: Campus.

Wallerstein, I. (2001). Unthinking Social Science. The Limits of Nineteenth-Century Paradigms. Philadelphia: Temple University Press.

Wallerstein, I. (2007). Abrir las ciencias sociales. México D. F.: Siglo XXI.

Weber, H. (2007, Diciembre). A Political Analysis of the Formal Comparative Method: Historicizing the Globalization and Development Debate [Análisis político del método comparativo formal: historizando el debate acerca de la globalización y el desarrollo]. Globalizations, 4(4), 559572. Doi: 10.1080/14747730701695828

Wimmer, A. y Glick, N. (2002, Octubre). Methodological Nationalism and Beyond: Nation-State Building, Migration and the Social Sciences [Nacionalismo metodológico y más allá: construcción del Estado-nación, migración y las ciencias sociales]. Global Networks, 2(4), 301-334. Doi: 10.1111/1471-0374.00043 